\title{
COMPARISON BETWEEN HYPERBARIC BUPIVACAINE PLUS FENTANYL AND HYPERBARIC BUPIVACAINE ALONE IN SPINAL ANESTHESIA FOR CAESAREAN SECTION
}

\author{
Fatima Iqbal, Manzoor Ahmed Faridi, Aisha Saeed, Inamullah Shah
}

Fauji Foundation Hospital, Rawalpindi Pakistan

\begin{abstract}
Objective: To compare the result of the combination of hyperbaric bupivacaine plus fentanyl with hyperbaric bupivacaine alone in patients undergoing caesarean section in spinal anaesthesia.

Study Design: Comparative, cross-sectional study.

Place and Duration of Study: Department of Anesthesia, Fauji Foundation Hospital, Rawalpindi Pakistan, from Dec 2017 to Jun 2018.

Methodology: After consulting the institutional ethical review committees a total of 60 females between ages $18-40$ years were enrolled for caesarean section delivery. They were divided into two groups. The study group $(n=30)$ received a subarachnoid injection of $0.5 \%$ hyperbaric bupivacaine $(10 \mathrm{mg}) 2 \mathrm{ml}$ with $25 \mathrm{ug}$ of fentanyl $0.5 \mathrm{ml}$ and control group $(\mathrm{n}=30)$ was injected $0.5 \%$ hyperbaric bupivacaine $12.5 \mathrm{mg}(2.5 \mathrm{ml})$ only. Pain experienced during the procedure was assessed by using 10-point visual analogue scoring method. The mean duration of analgesia, mean arterial blood pressure and heart rate after surgery were compared between two groups.

Results: The mean duration of analgesia was $206.5 / \mathrm{min} \pm 6.4$ in the study group and it was $163.6 \mathrm{~min} \pm 7.2$ in the control group $(p=0.001)$. Mean arterial BP after surgery was $92.3 \mathrm{mmHg} \pm 3.8$ in the study group and $88.7 \mathrm{mmHg} \pm 4.1$ in the control group $(p=0.001)$. The mean heart rate recorded after surgery was $75.2 / \mathrm{min} \pm 5.2$ in the study group and it was $70.4 / \mathrm{min} \pm 6.1$ in the control group $(p=0.001)$.

Conclusions: The mean duration of analgesia was significantly longer in the study group when compared with the control group with better mean arterial blood pressure and heart rate response after Caesarean section.
\end{abstract}

Keywords: Bupivacaine, Caesarean Delivery, Fentanyl.

This is an Open Access article distributed under the terms of the Creative Commons Attribution License (https://creativecommons.org/licenses/by-nc/4.0/), which permits unrestricted use, distribution, and reproduction in any medium, provided the original work is properly cited.

\section{INTRODUCTION}

Most caesarean sections are done under regional anesthesia which gives analgesia to the lower part of the body ${ }^{1}$. Spinal anesthesia is the most used method of the regional block in caesarean section, preferred for its rapid onset of action, effectiveness and protection against thromboembolic events ${ }^{2}$.

In caesarean section it is important to provide quality anesthesia that provides excellent analgesia to the mother. Local anesthetics, when used in moderate doses, cause vasodilatation which drops systemic vascular resistance resulting in hypotension along with motor and sensory blockade ${ }^{3}$. Maternal hypotension may have adverse effects on the fetus and is also associated with other symptoms such as nausea, vomiting, and dyspnea ${ }^{4}$.

Bupivacaine, an amide-type of a local anesthetic drug, is highly potent having slow onset (5-8 minutes) of action but lasts for a longer time (1.5-2 hours). For Caesarean section, intrathecal dose of hyperbaric bupivacaine is $12-15 \mathrm{mg}$ and its hyperbaric form is made by

Correspondence: Dr Manzoor Ahmed Fridi, Consultant Anaesthetist, Fauji Foundation Hospital, Rawalpindi Pakistan

Received: 16 Dec 2019; revised received: 01 Aug 2020; accepted: 08 Aug 2020 adding $8.25 \%$ glucose in it ${ }^{5}$.

Since the discovery of opioid receptors in spinal cord, an alternate therapy of epidural and intrathecal administration of narcotics has been introduced. This technique helps to avoid producing sympathetic blockade $^{6}$. Intrathecal short-acting lipophilic opioids given in combination with sub-therapeutic doses of local anesthetic, increase the level of analgesia because of synergistic effect ${ }^{7}$.

The most commonly used opioid is fentanyl which has high lipid solubility and more affinity for an opiate receptor following intrathecal administration ${ }^{8}$. Its onset of action takes around 5 minutes and the duration of analgesia is up to 30-40 minutes. Moreover, fentanyl provides effective analgesia and allows the intraoperative patient to experience no motor block, no sympatholytic effect and improves the anti-nociceptive effect of bupivacaine. It also prolongs postoperative analgesia with a lower occurrence of adverse drug reactions ${ }^{9}$.

The rationale of this study was to compare the effects of these drugs in pregnant patients in our demographic settings. If found to be effective, combination of intrathecal fentanyl with conventional hyperbaric 
bupivacaine would allow a reduced dose of bupivacaine, improve the quality of block, and prolong the duration of effective analgesia in patients undergoing Caesarean section. The objective of this study was to compare the results of intrathecal injection of combination of hyperbaric bupivacaine plus fentanyl with hyperbaric bupivacaine alone in patients undergoing caesarean section in spinal anesthesia.

\section{METHODOLOGY}

This comparative cross-sectional study was conducted at department of Anesthesia, Fauji Foundation Hospital, Rawalpindi from December 2017 to June 2018. Sample size was calculated by using WHO sample size calculator ${ }^{10}$. After approval from institutional Ethics Review Committee, a total of 60 patients were included (30 patients in each group) with their informed consent. Non-probability, consecutive sampling technique was used. All patients with uncomplicated pregnancy undergoing Cesarean section, in age group 18-40 years, with ASA status I and II and gestational age of $>37$ weeks were included. Patients with history of drug allergy, previous failed spinal anesthesia or in whom spinal anesthesia was contra-indicated due to other causes, were excluded. Patients with spinal deformity, BMI $>30$, fetal distress, or eclampsia (with fits, platelet count $<70000$ and proteinuria $>0.3$ grams in a 24 hours urine specimen) were also excluded.

Patients were assigned to the two treatment groups by lottery method. Study group received $0.5 \%$ hyperbaric bupivacaine $10 \mathrm{mg}(2.0 \mathrm{ml})$ with $25 \mathrm{mg}$ of fentanyl $(0.5 \mathrm{ml})$. Control group received $0.5 \%$ hyperbaric bupivacaine $12.5 \mathrm{mg}(2.5 \mathrm{ml})$ only. Systemic examination of each patient was carried out along with airway assessment and Mallampati score. Relevant laboratory investigations were checked. The function of anesthesia machine, endotracheal tube with a laryngoscope, and suction machine were checked. Availability of emergency drugs was confirmed. Intravenous access was secured with $18 \mathrm{G}$ cannula.

The patients received intravenous pre-hydration with $15 \mathrm{ml} / \mathrm{kg}$ of ringer's lactate solution. Baseline blood pressure, heart rate and oxygen saturation were noted. After these measures, the patients were placed in the sitting position and using aseptic precautions a skin wheal was raised at the chosen inter-space with $2 \%$ lignocaine using a 25 gauge needle. A lumbar puncture was then performed with a $25 \mathrm{G}$ pencil-point needle at the chosen space (preferably L3-L4). Access to subarachnoid space was confirmed by the free flow of CSF. The drug selected for each group was injected over 20 seconds. Oxygen was supplemented by Hudson mask.

Heart rate and blood pressure were recorded after every 5 minutes, 15 minutes, 30 minutes, 45 minutes, 60 minutes and then hourly till 6 hours. In case of hypotension observed before the procedure (MAP 20\% or more reduction from baseline), fast infusion of IV fluids was done along with phenylephrine in incremental doses $(5 \mathrm{mcg} / \mathrm{kg}$ ). Bradycardia (heart rate $<60 /$ $\mathrm{min}$ ) was treated with atropine injection $0.4-0.6 \mathrm{mg}$.

Perioperative pain was assessed by using a 10point visual analogue scoring method $(0-10 \mathrm{~cm}$ where $0=$ no pain and $10=$ worst pain ever felt). Systemic analgesic was not given until VAS was less than 4 . Intravenous tramadol $(50 \mathrm{mg}$ ) was given in case of pain. Duration between the time spinal block was administered to the time patient electively demanded pain relief was noted. This was considered as the duration of effective analgesia. All patients were observed for 24 hoursand readings of arterial blood pressure, heart rate and duration of analgesia were obtained. Data was recorded on a Performa by two persons for every patient.

Data was analyzed by IBM SPSS version 20. Mean and standard deviation was computed for quantitative variables. Frequency of percentage was calculated for qualitative variables. Independent samples t-test was used to compare the mean duration of postoperative analgesia, heart rate and mean arterial pressure between groups.

\section{RESULTS}

A total of sixty females between age 18-40 years who were planned for cesarean delivery were enrolled. The mean duration of analgesia, mean arterial blood pressure and heart rate after surgery was calculated and compared in both the groups. Mean age, height, weight and BMI of the study population were tabulated (table-I).

The mean duration of analgesia was $206.5 \mathrm{~min} \pm$ 6.4 in the study group and it was $163.6 \mathrm{~min} \pm 7.2$ in control group. The mean duration of analgesia was significantly longer in the study group when compared with the control group ( $p=0.001$, table-II). Mean arterial BP after surgery was $92.3 \mathrm{mmHg} \pm 3.8$ in a study group and it was $88.7 \mathrm{mmHg} \pm 4.1$ in the control group ( $p=0.001$ ) (table-III). The mean heart rate after surgery was $75.2 / \mathrm{min} \pm 5.2$ in the study group and it was $70.4 \mathrm{~min} \pm 6.1$ in the control group $(p=0.001)$ (table-IV). 
Hyperbaric Bupivacaine Plus Fentanyl \& Hyperbaric Bupivacaine $\quad$ Pak Armed Forces Med J 2021; 71 (3): $1033-36$

Table-I: Demographic characteristics of the study population.

\begin{tabular}{l|c|c|c|c}
\hline Groups & $\begin{array}{c}\text { Age } \\
\text { (Years) }\end{array}$ & $\begin{array}{c}\text { Height } \\
(\mathbf{m})\end{array}$ & $\begin{array}{c}\text { Weight } \\
\mathbf{( K g )}\end{array}$ & $\begin{array}{c}\text { Body Mass } \\
\text { Index }\left(\mathbf{k g} / \mathbf{m}^{2}\right)\end{array}$ \\
\hline Study Group & $25.5 \pm$ & $1.6 \pm$ & $65.7 \pm$ & $24.3 \pm 2.5$ \\
(Mean) & 5.8 & 0.06 & 5.1 & \\
\hline Control Group & $26.1 \pm$ & $1.7 \pm$ & $68.8 \pm$ & $24.1 \pm 2.1$ \\
(Mean) & 6.1 & 0.05 & 6.4 & \\
\hline
\end{tabular}

Table-II: Mean duration of analgesia in both groups.

\begin{tabular}{l|c|c}
\hline Group & $\begin{array}{c}\text { Duration of Analgesia } \\
\text { (Minutes) }\end{array}$ & $p$-value \\
\hline Study Group (Mean) & $206.5 \pm 6.4$ & \multirow{2}{*}{0.001} \\
\hline Control Group (Mean) & $163.6 \pm 7.2$ & \\
\hline
\end{tabular}

Table-III: Mean arterial blood pressure post-surgery in both groups.

\begin{tabular}{|c|c|c|}
\hline Group & $\begin{array}{l}\text { Mean Arterial BP } \\
(\mathrm{mmHg})\end{array}$ & $p$-value \\
\hline Study Group (Mean) & $92.3 \pm 3.8$ & \multirow{2}{*}{0.001} \\
\hline Control Group (Mean) & $88.7 \pm 4.1$ & \\
\hline \multicolumn{3}{|c|}{ Table-IV: Mean heart rate post-surgery in both groups. } \\
\hline Group & Heart Rate (per min) & $p$-value \\
\hline Study Group & $75.2 \pm 5.2$ & \multirow{2}{*}{0.001} \\
\hline Control Group & $70.4 \pm 6.1$ & \\
\hline
\end{tabular}

\section{DISCUSSION}

The results of this study show that a combination of hyperbaric bupivacaine with fentanyl provides a longer analgesia as compared to hyperbaric bupivacaine alone in patients undergoing C-section in spinal anesthesia $(p=0.001)$. The duration of postoperative analgesia was also notably longer in the group that received fentanyl and hyperbaric bupivacaine as compared to the group that received hyperbaric bupivacaine alone $(p=0.001)$. This study also revealed that patients maintained a higher blood pressure with combination drugs as compared to local anesthetic alone $(p=0.001)$. Mean heart rate in the study group was higher relative to the control group $(p=0.001)$. These findings are in conformity with previous studies that compared these two methods of spinal anesthesia. A study conducted in India ${ }^{5}$, reported a significant $(p=$ 0.001 ) fall of blood pressure ( $>25 \%$ fall from the baseline) with hyperbaric bupivacaine alone (98.76 \pm 8.3$)$ as compared to fentanyl and hyperbaric bupivacaine (117.32 \pm 12.2$)$. The study also reported a fall in heart rate in both groups $(87.09 \pm 9.36$ vs $79.24 \pm 11.63)$ but, unlike our study, the difference between the groups was not statistically significant ( $p=0.001$ ).

Kashmiri et al11, in a study conducted in 2015 at Karachi, comparedthe two methods in elective lower abdominal and lower limb orthopedic surgeries in a sample size of 60 patients. Their results are similar to our study in that duration of analgesia after the operation was reported to be significantly longer $(p=005)$ in the group that received a combination of hyperbaric bupivacaine and fentanyl as compared to control group that received hyperbaric bupivacaine alone $(249.87 \pm 32.59$ vs $161.97 \pm 25.55)$.

Dosage of local anaesthetic use in different studies varies between $7.5 \mathrm{mg} 5$ to $10 \mathrm{mg} \mathrm{12}$, when used in combination with adjuvant drugs. In our study we used $10 \mathrm{mg}$ bupivacaine when used in combination with fentanyl.

Makwana et al12, conducted a study in 2014 to observe the effectiveness of spinal bupivacaine alone compared with a mixture of bupivacaine and fentanyl in major gynecological surgeries. The purpose of this study was to compare perioperative hemodynamic stability and postoperative analgesia using these two methods. Their findings are in concordance with our study as theyreported a longer duration of sensory block and analgesia with combination of the two drugs as compared to Bupivacaine alone.

Hyperbaric bupivacaine has been used with several adjuvant agents to prolong the duration of spinal analgesia including combination with dexmedetomidine and ketamine. A study conducted in China in 2015 by Sun et $\mathrm{ll}^{13}$, compared the effects of bupivacaine alone, bupivacaine plus fentanyl, and bupivacaine plus dexmedetomidine for postoperative pain management in patient planned for Cesarean section under intrathecal block. They did a trial on 90 patients who were randomly divided into 3 groups. Our study compares favorably with their results in that they reported sensory block to be significantly longer in bupivacaine plus fentanyl and bupivacaine plus dexmedetomidine as compared tobupivacaine alone. The occurrence of postoperative pain was also delayed in the groups having two drugs compared to Bupivacaine alone. A four group comparative study conducted on 84 patients in China (2015) by Li et al ${ }^{14}$, compared the effects of bupivacaine alone, bupivacaine plus fentanyl, bupivacaine with clonidine and bupivacaine plus dexmedetomidine on quality of spinal blockade for Cesarean section. The results of this study are similar to Sun et $a l^{12}$, and compare favorably with our results.

Hyperbaric bupivacaine alone was compared with combination of this drug with subarachnoid ketamine and subarachnoid fentanyl respectively in a study on 100 healthy females undergoing Cesarean section surgery by Bhattarai et al, at Kathmandu15. Effectiveness and duration of analgesia was reported to be better with hyperbaric bupivacaine with fentanyl. 
Their results were similar to those of our study although the dose of bupivacaine in their study was 10 mg for both groups.

More studies are needed to compare the effects of lesser doses of bupivacaine in combination with fentanyl, to determine the minimum dose required to achieve effective analgesia without associated symptoms like nausea.

\section{CONCLUSION}

Hyperbaric bupivacaine combined with fentanyl provides longer analgesia and is safer in terms of hemodynamics, when used for spinal anesthesia, than hyperbaric bupivacaine alone.

\section{CONFLICT OF INTEREST}

This study has no conflict of interest to be declared by any author.

\section{REFERENCES}

1. Balkan B, Yektas A. Effects of levobupivacaine at different doses with fentanyl added on intrathecal anesthesia for cesarean section. Ann Clin Lab Res 2018; 7(1): 286-92.

2. Benzouina S, Boubkraoui Mel-M, Mrabet M, Chahid N, Kharbach A, El-Hassani A, et al. Fetal outcome in emergency versus elective cesarean sections at Souissi Maternity Hospital, Rabat, Morocco. Pan Afr Med J 2016; 23(1): 197-96.

3. Atalay C, Karaca M, Naldan ME, Soyalp C, Kursad H. Fentanyl with low dose bupivacaine (isobaric and hyperbaric) and levo bupivacaine for combined spinal-epidural technique in cesarean section. Medicine Sci 2018; 7(3): 494-98.

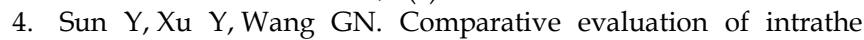
calbupivacaine alone, bupivacaine-fentanyl, and bupivacainedexmedetomidine in Caesarean section. Drug Res (Stuttg) 2015; 65(9): 468-72.

5. Venkata HG, Pasupluleti S, Pabbu UG, Porika S, Talari G. A randomized controlled prospective study comparing a low dose bupivacaine and fentanyl mixture in a conventional dose of hyperbaric bupivacaine for cesarean section. Saudi J Anaesth 2015; 9(2): 122-27.
6. Capdevila X, Aveline C, Delaunay L, Bouaziz H, Zetlaoui P, Choquet $\mathrm{O}$, et al. Factors determining the choice of spinal versus general anesthesia in patients undergoing ambulatory surgery: results of a multicenter observational study. Adv Ther 2020; 37(1): 527-40.

7. Weigl W, Bieryło A, Wielgus M, Krzemień-Wiczyńska S, Kołacz M, Dąbrowski MJ. Perioperative analgesia after intrathecal fentanyl and morphine or morphine alone for cesarean section: A randomized controlled study. Medicine (Baltimore) 2017; 96(48): e8892-95.

8. Sun S, Wang J, Bao N, Chen Y, Wang J. Comparison of dexmedetomidine and fentanyl as local anesthetic adjuvants in spinal anesthesia: a systematic review and meta-analysis of randomized controlled trials. Drug Des Devel Ther 2017; 11(1): 3413-24.

9. Gurunath BB, Madhusudhana R. Postoperative analgesic efficacy of intrathecal fentanyl compared to nalbuphine with bupivacaine in spinal anesthesia for lower abdominal surgeries. Anesth Essays Res 2018; 12(2): 535-38.

10. Benhamou D, Thorin D, Brichant JF, Dailland P, Milon D, Schneider M. Intrathecal clonidine and fentanyl with hyperbaric bupivacaine improves analgesia during cesarean section. Anesth Analg 1998; 87(3): 609-13.

11. Kashmiri ZA, Islam SKU. Effect of intrathecal fentanyl on the duration of postoperative analgesia. Comparison between inj. bupi-vacaine with inj. fentanyl and inj. Bupivacaine alone, in elective lower abdominal and lower limb orthopaedic surgeries. Pak J Surj 2015; 31(3): 161-64.

12. Makwana J, ShivrajTN, Khade A, Bansal S, Mandal N, Goswami $\mathrm{S}$, et al. Comparison between hyperbaric bupivacaine and hyperbaric Bupivacaine plus fentanyl intrathecally in major gynaecologicalsurgeries. Int J Med Sci Public Health 2014; 3(3): 319-22.

13. Sun $Y, X u$ Y. Comparative evaluation of intrathecal bupivacaine alone, bupivacaine-fentanyl, and bupivacaine-dex-medetomidine in caesarean section. Drug Res (Stuttg) 2015; 65(9): 468-72.

14. Li Z, Tian M, Zhang CY, Li AZ, Huang AJ, Shi CX, et al. A randomised controlled trial to evaluate the effectiveness of intrathecal bupivacaine combined with different adjuvants (fentanyl, clonidine and dexmedetomidine) in caesarean section. Drug Res (Stuttg) 2015; 65(11): 581-86.

15. Bhattarai B, Shah R. Comparative study of hyperbaric bupivacaine plus ketamine vs bupivacaine plus fentanyl for spinal anaesthesia during caesarean section. Kathmandu Univ Med J 2013; 11(44): 287-91. 